\title{
Immune responses to the hepatitis B surface antigen and liver-specific lipoprotein in acute type B hepatitis
}

\author{
W. M. LEE 1 , W. D. REED ${ }^{2}$, C. G. OSMAN, J. VAHRMAN, A. J. ZUCKERMAN, \\ A. L. W. F. EDDLESTON, AND ROGER WILlIAMS
}

From the Liver Unit, King's College Hospital and Medical School, Denmark Hill, London, The Western Hospital, and the Hepatitis Research Unit, London School of Hygiene and Tropical Medicine, London

SUMMARY A serial prospective study of cellular immunity to HBsAg and liver-specific membrane lipoprotein was undertaken in 21 adults with acute hepatitis type B. Cellular immunity to $\mathrm{HBs} \mathrm{Ag}$ as determined by leucocyte migration inhibition with partially purified HBsAg as antigen was detected in all the patients during the recovery phase of the illness and was already detectable at the time of admission in $13(62 \%)$ of the cases. In five of the remaining eight the titre of HBsAg in the serum at this time was high and in the whole series there was an inverse correlation between the degree of migration inhibition on admission and the peak $\mathrm{HBsAg}$ titre suggesting that antigen or possibly antigen/antibody complexes might be interfering with the demonstration of cellular immunity in vitro. Using a combination of minimum migration index recorded during the recovery period and peak HBsAg titre, it was possible to compute the peak aspartate aminotransferase level with reasonable accuracy, a finding consistent with the hypothesis that the severity of the illness is related to both the number of infected hepatocytes and the vigour of the immune response to HBsAg. Evidence of an immune response to the liver-specific hepatocyte membrane lipoprotein was present in $50 \%$ of the patients tested at the time of admission, but was transient, having disappeared in every case by four weeks. The minimum migration index recorded with $\mathrm{HBsAg}$ as antigen was significantly lower in those with detectable sensitisation to the lipoprotein and it is possible that this autoimmune reaction is also generated by the interaction of $\mathrm{T}$ cells with viral antigenic determinants on the liver cell surface.

There has been considerable interest in recent years in the relationship between immune responses to the hepatitis B surface antigen and the liver cell injury of acute type B hepatitis. Several lines of evidence suggest that the hepatitis B virus is not cytopathogenic and that liver damage may be the result of immune-mediated destruction of infected hepatocytes (Dudley et al., 1972a; Eddleston, 1976). In almost all patients with acute hepatitis $B$ infection a cell-mediated response to HBsAg can be demonstrated after recovery (Yeung Laiwah et al., 1973; Irwin et al., 1974; Reed et al., 1974), but there is

1Present address: Department of Medicine, Columbia University College of Physicians and Surgeons, 630 West 168th Street, New York, N.Y. 10032, USA.

${ }^{2}$ Present address: Department of Medicine, Sir Charles Gairdner Hospital, University of Western Australia, Shenton Park, W.A. 6008, Australia.

Received for publication 11 October 1976 conflicting evidence as to how early in the illness this can be detected. We report here the results of a serial prospective study of the cellular and humoral immune response to $\mathrm{HBsAg}$ in 21 cases of acute hepatitis type B, all of whom were followed from the time of presentation until antigen clearance was complete and the standard biochemical liver function tests had returned to normal.

Since we have postulated that $T$ lymphocytes reacting with $\mathrm{HBsAg}$ on the surface of infected hepatocytes may not only destroy these cells but could also initiate an autoimmune reaction responsible for continued liver damage in chronic active hepatitis (Eddleston and Williams, 1974), we have taken the opportunity provided by the present study to test one aspect of this hypothesis.

\section{Methods}

Sera from 41 patients with acute hepatitis admitted 
consecutively over a six month period to an infectious disease hospital serving the inner London area were screened by immunodiffusion and electrophoresis for the presence of HBsAg. Twenty-three were found to be antigen positive, and further samples for immunological study were obtained from these twice weekly in hospital and weekly through the convalescence period. Two patients were lost to follow-up before antigen clearance had occurred and have been excluded from the study. In addition to complete history, physical examination, and daily clinical visits, serum aspartate aminotransferase (AST), alkaline phosphatase, and bilirubin levels were measured weekly.

\section{IMMUNOLOGICAL STUDIES}

Each serum sample was tested for HBsAg and antiHBs by immunodiffusion and immunoelectrophoresis (World Health Organisation, 1970) and radioimmunoassay (Reed et al., 1973, 1974). The titre of hepatitis B surface antigen was determined by complement fixation (Bradstreet and Taylor, 1962). Serum autoantibodies reacting with smooth muscle were sought by indirect immunofluorescence (Doniach et al., 1966) initially and at two weeks and three months after admission.

\section{PREPARATION OF ANTIGENS}

\section{Hepatitis $B$ surface antigen}

Partially purified HBsAg was prepared from sera known to contain the antigen in high titre. Forty millilitre volumes were applied to a column $(5 \mathrm{~cm} \times$ $50 \mathrm{~cm}$ ) containing Sepharose 6B equilibrated with $.02 \mathrm{M}$ phosphated-buffered saline (PBS) at $\mathrm{pH} 7 \cdot 2$. The effluent was collected in $5 \mathrm{ml}$ fractions and tested for $\mathrm{HBsAg}$ by a Latex agglutination technique (Pfizer Ltd). Antigen-positive fractions were concentrated by pressure filtration over a UM 10 membrane in a stirred cell (Dialaflo Ltd) and further purified by a second passage through Sepharose 6B. Fractions were again tested for HBsAg by Latex agglutination and those of highest titre were pooled, concentrated, and dialysed against PBS.

Eight different preparations were used in the present study, six being made from sera from healthy HBsAg carriers and two from sera from patients with chronic liver disease (the liver biopsy appearances were of chronic persistent hepatitis in one case and chronic aggressive hepatitis in the other). Before the introduction of a new batch, tests were performed with both new and old preparations in parallel to establish that there were no significant differences in their behaviour in the leucocyte migration test.

\section{Liver-specific lipoprotein}

This antigen was prepared by sequential gel filtration of the $40000 \times \mathrm{g}$ supernatant of a human liver homogenate as described elsewhere (Miller et al., 1972) and stabilised for storage at $4^{\circ} \mathrm{C}$ by adding $1 \mathrm{mM}$ EDTA to the tris-HCl- $\mathrm{NaCl}$ buffer (Eddleston et al., 1973). Recent analyses including preparation of the apoprotein have confirmed the homogeneous nature of this material and its localisation to the hepatocyte surface membrane (McFarlane et al., 1977).

LEUCOCYTE MIGRATION TEST

A micromodification of the leucocyte migration technique was used (Mitchell et al., 1972) with fetal calf serum selected for maximum sensitivity (Mitchell and Eddleston, 1973). The optimum concentration of partially purified $\mathrm{HBsAg}$ to be used in the test chambers was determined for each batch by constructing dose response curves using peripheral blood leucocytes obtained from healthy members of the laboratory staff whose immune status with regard to $\mathrm{HBsAg}$ was known from repeated tests of both cellular and humoral immunity (Reed et al., 1974). At high concentrations all the antigen preparations produced toxic inhibition of leucocyte migration, while at much lower levels there was no inhibition of migration with leucocytes from any of the subjects tested. However, at optimum concentrations leucocytes from the immune individuals demonstrated inhibition of migration, while those of non-sensitised subjects did not. This concentration was then adopted for testing patients. The normal range for migration indices using $\mathrm{HBsAg}$ was found to be $0 \cdot 80-1 \cdot 10$ and indices less than 0.80 were considered positive responses.

The same leucocyte migration technique was employed to detect cellular immunity to the liverspecific lipoprotein antigen. Using $50 \mathrm{ug}$ of the lipoprotein to each millilitre of culture medium in the test chambers the normal range of migration indices (mean $\pm 2 \mathrm{SD}$ in normal subjects) was $0.75-1.05$ and any result outside this range was considered positive.

\footnotetext{
SPECIFICITY OF LEUCOCYTE MIGRATION RESPONSE TO HBSAg

On immune electron microscopy, the final preparation of partially purified $\mathrm{HBsAg}$ contained predominantly small round forms of $\mathrm{HBsAg}$ with some tubules, although occasional batches had a very small number of Dane particles. Free core material was never seen. In two of the recent preparations it has been possible to test for the presence of $e$ antigen (El Sheikh et al., 1975). This was detected in one of the samples from the patient with chronic
} 
persistent hepatitis but in the other, from a healthy carrier, the starting serum contained e antibody, and neither e antigen nor anti e could be detected in the preparation used in the leucocyte migration test. The results obtained with these two preparations in the leucocyte migration test were not significantly different in spite of the obvious differences in minor antigenic constituents. Control antigen preparations from HBsAg negative blood consistently gave negative results when used in the leucocyte migration test.

\section{Results}

\section{NORMAL SUBJECTS}

Serial observations of leucocyte migration with $\mathrm{HBs} \mathrm{Ag}$ as antigen were obtained in four members of the laboratory staff over a period of three months. In three of them, observations had also been made one year previously (Reed et al., 1974) and the two who had then shown evidence of sensitisation, including the presence of anti HBs, continued to demonstrate migration inhibition on every occasion on which the test was performed (Fig. 1). In contrast, the other subject (one of the unit secretaries) in whom the previous results had been normal and another research fellow, who had only recently joined the staff, never showed migration inhibition over the three month follow-up period. A change in the pattern of migration was observed in one subject (W. L.), also newly arrived in the unit, who was working closely with $\mathrm{HBsAg}$ positive sera and partially purified material (Fig. 2). Although the first six migration indices were within the normal range, the next seven observations, beginning 10 weeks after he joined the project, were clearly different, showing significant migration inhibition. Analysis of the results in this subject using the mean square successive difference test (Hart, 1942) confirmed the presence of a significant long-term non-random effect to reduce the migration indices $(P<0.05)$. Some six months later, anti HBs was first detected in the serum by radioimmunoassay but this change in reactivity was not accompanied by any clinical or biochemical evidence of acute hepatitis.

\section{PATIENTS With HePatitis}

Clinical data on the 17 men and four women with HBsAg-positive hepatitis is shown in Table 1 . Peak serum bilirubin levels ranged from 70-533 $\mu \mathrm{mol} / 1$ and peak serum AST from 56-3080 IU/1. Virtually all the patients required hospitalisation for at least two weeks and could be considered to have had moderately severe hepatitis. Eleven of the men were homosexual and one was a drug user. Another was a medical immunologist who had worked closely with several antigen positive sera at a referral

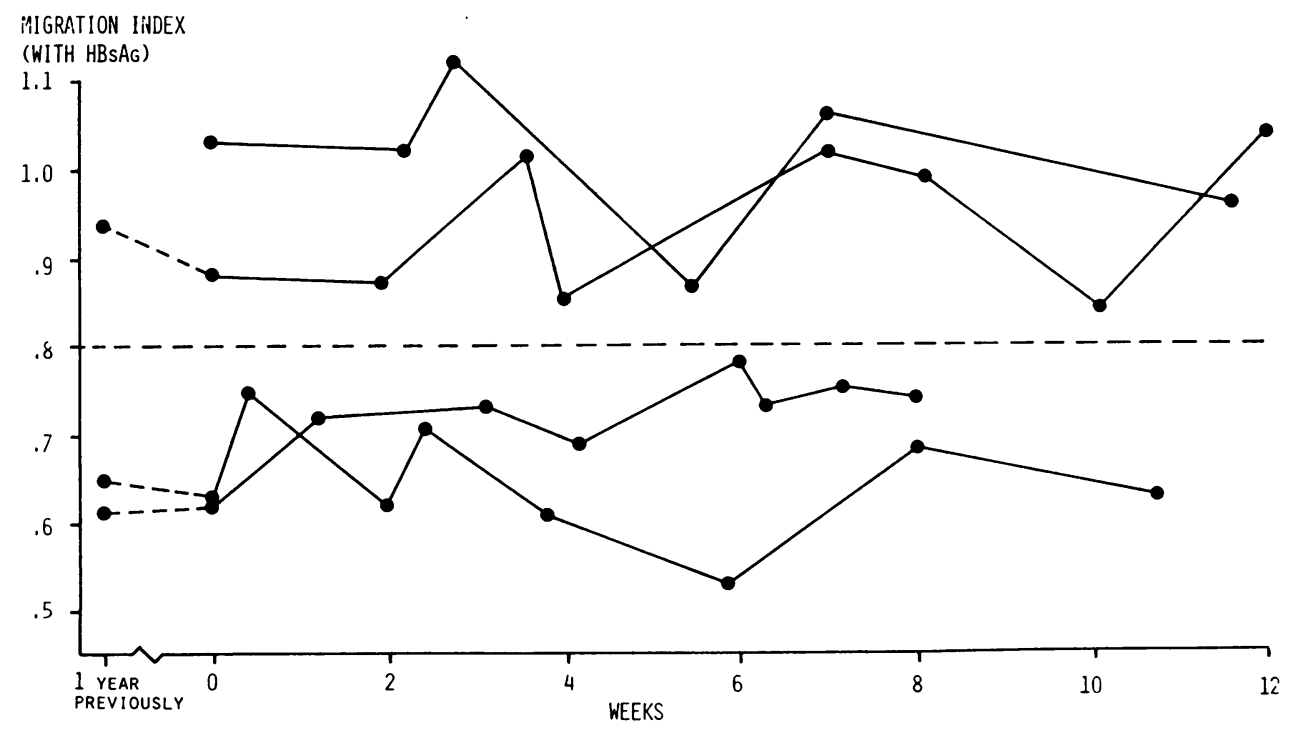

Fig. 1 The results of leucocyte migration tests with HBsAg as antigen in four members of the laboratory staff studied repeatedly over a 12 week period. The horizontal dotted line indicates the lower limit of normal for the migration index. The results obtained in three of the individuals in a survey carried out one year previously (Reed et al., 1974) are also shown. 


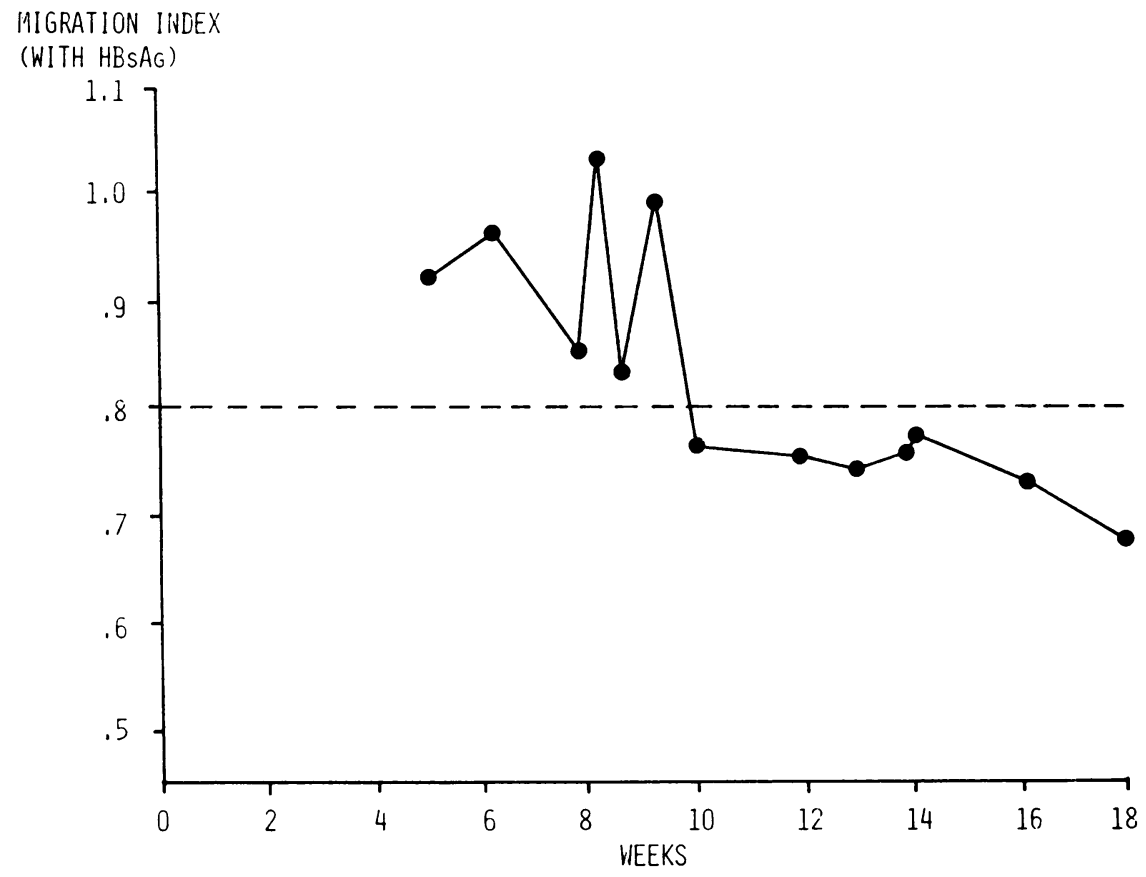

Fig. 2 Serial measurements of the migration index with $\mathrm{HBsAg}$ as antigen in one member of the laboratory staff who was working closely with HBs Ag positive material. A definite change in reactivity is apparent, beginning 10 weeks after he joined the unit.

laboratory. The sexual partner of one of the women was found to be an asymptomatic HBsAg carrier. In the remaining seven patients a putative source was not apparent.

The initial titre of HBsAg by complement fixation ranged from $1 / 8$ to $1 / 4096$ (Table 2). In all cases the amount of antigen detected in the serum declined exponentially during the course of the illness and there was therefore a linear relationship between antigen titre and time. HBsAg was no longer detectable in any of the cases by immunoelectrophoresis after six weeks and by 13 weeks radioimmunoassay was also negative. The mean time from admission to complete antigen clearance as determined by radioimmunoassay was 31 days or an estimated 39 days (range 13-63) after the onset of the illness.

Anti HBs was detected only by radioimmunoassay and usually only during convalescence, although in five patients a positive result was obtained while antigenaemia was still present. However, this was observed only when the antigen levels were low (1/16 or less by complement fixation or detected by radioimmunoassay only). In 12 of 13 patients followed for 20 weeks or more, antibody to $\mathrm{HBsAg}$ was eventually detected-in one as late as 19 weeks after hospital admission.
The results obtained by using the leucocyte migration test with $\mathrm{HBsAg}$ as antigen, showed that inhibition of migration was already detectable at the time of admission in $13(62 \%)$ of the patients (Table 2). Of the eight patients in whom migration inhibition was not initially present, five had titres of $\mathrm{HBsAg}$ in the serum greater than $1 / 128$ by complement fixation and for the whole group of 21 patients there was a significant correlation between the migration index at the time of admission and the peak titre of HBsAg $(r+0.51, \mathrm{P}<0.05)$. As the HBsAg level in the serum fell during recovery, migration inhibition was detected in all the patients, although the minimum migration index recorded varied considerably from case to case (range 0.38 to 0.75 , Table 2 ).

RELATIONSHIP BETWEEN SEVERITY OF LIVER DAMAGE AND IMMUNE RESPONSE TO HBSAg Although there was a poor correlation overall between the peak aspartate aminotransferase level and the peak HBsAg titre $(r+0 \cdot 31)$, six of the 12 patients with a maximum aminotransferase level of more than $500 \mathrm{IU} / \mathrm{l}$ had titres of $\mathrm{HBsAg}$ of $1 / 512$ or greater as compared with none of the nine with lower enzyme levels ( $P=0.02$ by Fisher exact test). While there was no relationship between the peak 
Table 1 Relevant clinical and biochemical data (peak values shown) in 21 patients with acute hepatitis type B

\begin{tabular}{|c|c|c|c|c|c|c|}
\hline Patient & $\operatorname{Age}(\mathrm{J} r)$ & $\operatorname{Sex}$ & Source & $\begin{array}{l}\text { Admission day after } \\
\text { onset }\end{array}$ & $\begin{array}{l}\text { Aspartate } \\
\text { aminotransferase } \\
(I U / I)\end{array}$ & $\begin{array}{l}\text { Serum bilirubin } \\
(\mu \mathrm{mol} / \mathrm{l})\end{array}$ \\
\hline 1 & 37 & $\mathbf{F}$ & $\begin{array}{l}\text { Boyfriend HBsAg + } \\
\text { carrier }\end{array}$ & 9 & 3080 & 285 \\
\hline 2 & 23 & $\mathbf{M}$ & Homosexual & 11 & 880 & 172 \\
\hline 3 & 26 & $\mathbf{M}$ & Homosexual & 16 & 125 & 195 \\
\hline 4 & 34 & $\mathbf{M}$ & Homosexual & 18 & 290 & 140 \\
\hline 5 & 19 & $\mathbf{F}$ & ? & 9 & 900 & 103 \\
\hline 6 & 21 & $\mathbf{F}$ & ? & 11 & 243 & 70 \\
\hline 7 & 33 & $\mathbf{M}$ & $?$ & 16 & 760 & 433 \\
\hline 8 & 28 & $\mathbf{M}$ & $\begin{array}{l}\text { Occupation as } \\
\text { immunologist }\end{array}$ & 14 & 2200 & 105 \\
\hline 9 & 33 & $\mathbf{M}$ & Homosexual & 17 & 209 & 150 \\
\hline 10 & 56 & $\mathbf{M}$ & $?$ & 28 & 120 & 233 \\
\hline 11 & 21 & $\mathbf{M}$ & Drug user & 5 & 920 & 113 \\
\hline 12 & 22 & $\mathbf{M}$ & Homosexual & 12 & 650 & 383 \\
\hline 13 & 52 & $\mathbf{M}$ & $\begin{array}{l}\text { Recent gastric } \\
\text { surgery. Not } \\
\text { transfused }\end{array}$ & 5 & 370 & 417 \\
\hline 14 & 28 & $\mathbf{M}$ & Homosexual & 18 & 56 & 117 \\
\hline 15 & 37 & $\mathbf{M}$ & $?$ & 9 & 830 & 212 \\
\hline 16 & 42 & $\mathbf{M}$ & Homosexual & 8 & 1120 & 400 \\
\hline 17 & 32 & $\mathbf{M}$ & Homosexual & 19 & 800 & 533 \\
\hline 18 & 29 & $\mathbf{M}$ & Homosexual & 7 & 150 & 157 \\
\hline 19 & 29 & $\mathbf{M}$ & Homosexual & 8 & 380 & 110 \\
\hline 20 & 28 & $\mathbf{M}$ & Homosexual & 13 & 770 & 122 \\
\hline 21 & 24 & $\mathbf{F}$ & $?$ & 7 & 1020 & 217 \\
\hline
\end{tabular}

Table 2 Relationship between peak aspartate aminotransferase values and migration index with $\mathrm{HBs}$ Ag and peak titre of $\mathrm{HBs} \mathrm{Ag}$ in serum of 21 patients with acute hepatitis $B$

\begin{tabular}{|c|c|c|c|c|}
\hline \multirow[t]{2}{*}{ Case no. } & \multirow[t]{2}{*}{ Peak aspartate aminotransferase } & \multicolumn{2}{|c|}{ Migration index (with HBsAg) } & \multirow[t]{2}{*}{ Peak titre of $\mathrm{HBsAg}$} \\
\hline & & Minimum & Initial & \\
\hline 1 & 3080 & 0.52 & 0.66 & $1 / 32$ \\
\hline 8 & 2200 & 0.45 & 0.71 & $1 / 512$ \\
\hline 16 & 1120 & 0.61 & 0.61 & $1 / 512$ \\
\hline 21 & 1020 & 0.54 & 0.82 & $1 / 512$ \\
\hline 11 & 920 & $0 \cdot 38$ & 0.79 & $1 / 64$ \\
\hline 5 & 900 & 0.61 & 0.73 & $1 / 1024$ \\
\hline 2 & 880 & 0.64 & 0.94 & $1 / 64$ \\
\hline 15 & 830 & 0.64 & 1.00 & $1 / 2048$ \\
\hline 17 & 800 & 0.61 & 0.78 & $1 / 256$ \\
\hline 20 & 770 & 0.54 & 0.59 & $1 / 16$ \\
\hline 7 & 760 & 0.58 & 0.58 & $1 / 128$ \\
\hline 12 & 650 & 0.65 & $1 \cdot 10$ & $1 / 4096$ \\
\hline 13 & 370 & 0.50 & 0.86 & $1 / 32$ \\
\hline 19 & 380 & 0.63 & 0.86 & $1 / 256$ \\
\hline 4 & 290 & 0.59 & 0.74 & $1 / 8$ \\
\hline 6 & 243 & 0.57 & 0.76 & $1 / 256$ \\
\hline 9 & 209 & 0.50 & 1.05 & $1 / 256$ \\
\hline 18 & 150 & 0.71 & 0.71 & $1 / 128$ \\
\hline 3 & 125 & 0.58 & 0.62 & $1 / 16$ \\
\hline 10 & 120 & 0.75 & 0.92 & $1 / 128$ \\
\hline 14 & 56 & 0.57 & 0.57 & $1 / 32$ \\
\hline
\end{tabular}

aspartate aminotransferase levels and the initial migration index ( $r 0.01)$, there was some association between the enzyme level and the minimum value recorded for the migration index $(r-0 \cdot 37$, $\mathrm{P}<0 \cdot 1>0.05$ ). When the combination of $\mathrm{HBs} \mathrm{Ag}$ titre and minimum migration index was considered there seemed to be a closer relationship with the peak aminotransferase level. This is seen particularly clearly in the last four cases in Table 2, all of whom have relatively low aspartate aminotransferase levels. In two (cases 18 and 10), the HBsAg titre was moderately high at $1 / 128$ but there was only weak inhibition of migration with minimum migration indices of 0.71 and 0.75 . In contrast, migration inhibition was more marked in cases 3 and 14 with indices of 0.58 and 0.57 respectively, but the titres of HBsAg were low (1/16 and 1/32). By multiple regression analysis it was shown that the most 
Table 3 Comparison of results of some biochemical and immunological tests in patients with and without evidence of sensitisation to liver-specific membrane lipoprotein

\begin{tabular}{|c|c|c|c|}
\hline & \multicolumn{2}{|c|}{ Leucocyte migration inhibition with liver-specific lipoprotein as antigen } & \\
\hline & Present $(N=8)$ & Ahsent $(N=8)$ & \\
\hline $\begin{array}{l}\text { Peak aspartate aminotransferase } \\
\left(\log _{10} I U / 1\right)\end{array}$ & $2.82 \pm 0.55$ & $2.56 \pm 0.35$ & $p>0 \cdot 2^{*}$ \\
\hline $\begin{array}{l}\text { Peak titre of } \mathrm{HBsAg} \\
\left(\log _{2} \text { titre }{ }^{-1}\right) \\
\text { Migration index with } \mathrm{HBsAg}\end{array}$ & $6 \cdot 87 \pm 2 \cdot 36$ & $7 \cdot 25 \pm 3 \cdot 10$ & $\mathrm{p}>0.7$ \\
\hline $\begin{array}{l}\text { Migration index with HBsAg } \\
\text { minimum } \\
\text { initial }\end{array}$ & $\begin{array}{l}0.52 \pm 0.08 \\
0.74 \pm 0.19\end{array}$ & $\begin{array}{l}0.60 \pm 0.06 \\
0.77 \pm 0 \cdot 16 \\
43 \%(3 / 7)\end{array}$ & $\begin{array}{l}p<0.05 \\
p>0.7 \\
p=0.07\end{array}$ \\
\hline $\begin{array}{l}\text { Smooth muscle antibody } \\
\text { positive }\end{array}$ & & & \\
\hline
\end{tabular}

*By Student's $t$ test

†By Fisher's exact test

accurate prediction of the peak aminotransferase level was obtained from the formula:

$\log _{10}$ peak aminotransferase level $=$

$\left(0.0767 \times \log _{2} \mathrm{HBsAg}\right.$ titre $)-$

$(2.44 \times$ minimum migration index $)+3.5564$.

Using this relationship, the multiple regression coefficient for the predicted and observed values of the aminotransferase was $0.54(\mathrm{P}<0.05)$.

\section{IMMUNE RESPONSE TO LIVER MEMBRANE LIPOPROTEIN}

Of 16 patients in whom the leucocyte migration test was also performed with the liver specific lipoprotein as antigen, eight $(50 \%)$ showed abnormal migration indices at the time of admission. This sensitisation was transient, having disappeared by the fourth week. Comparison of clinical and immunological results in those with and without evidence of this autoimmune response showed no significant differences in peak aspartate aminotransferase levels or titre of HBsAg (Table 3). Although there was also no difference between the two groups in the initial migration indices with $\mathrm{HBsAg}$ as antigen, the minimum values recorded for the migration indices with HBsAg were significantly lower in those with sensitisation to the lipoprotein than in those without. There was also a difference between the groups in the frequency of antibodies reacting with smooth muscle antigens but this did not reach statistical significance (Table 3).

\section{Discussion}

Although the HBsAg preparations used in the leucocyte migration test in the present study were only partially purified, the consistent results obtained with antigen preparations from many different samples of $\mathrm{HBsAg}$ positive blood and the completely negative results with control preparations made from normal serum suggested that $\mathrm{HBsAg}$ was the major antigenic constituent of the active preparations. These observations also suggested that $\mathrm{HBsAg}$ was responsible for the inhibition of leucocyte migration observed in the sensitised normal subjects and the patients studied. Thus the finding of migration inhibition in more than $60 \%$ of the patients when first tested supports the concept of immune-mediated liver cell damage in acute hepatitis. It has been suggested that the tissue damage is due to T lymphocytes reacting with HBsAg on the surface of infected hepatocytes (Eddleston and Williams, 1974) and in support of this Alberti et al. (1975), in a preliminary report, have identified membraneassociated HBsAg on a small proportion of hepatocytes isolated from liver biopsies taken soon after the onset of acute type B hepatitis. It is not possible from the present study to be sure that $T$ lymphocytes alone are involved for, although the leucocyte migration test does seem in some experiments to be entirely $\mathrm{T}$ cell dependent (Fimmel, 1975), there is also evidence suggesting that other cell types can release migration inhibitory factors (Rocklin et al., 1974) and even that circulating or cytophilic antibody can influence the result (Brostoff, 1974).

The finding of negative results initially on the leucocyte migration test in many of the patients with high titres of HBsAg suggested the possibility that antigen or antigen/antibody complexes were blocking $T$ cell function. The significant correlation between peak HBsAg titre and initial migration index, and the appearance of migration inhibition in all cases when $\mathrm{HBsAg}$ levels fell, further supported this concept. Indeed, similar findings had also been obtained in an earlier study of cellular immunity to HBsAg in chronic hepatitis (Lee et al., 1975). This situation may be similar to that proposed in patients and animals with extensive neoplastic disease where circulating tumour antigens or antigen/antibody complexes appear to block lymphocytes cytotoxic to tumour cells in vitro (Baldwin et al., 1973). 
Extensive washing of the lymphocytes often restores their cytotoxic potential (Currie and Basham, 19?2) and it may be that differences in methods of preparing leucocytes and in antigen concentrations are responsible for the variation in the reported frequency of positive results in the leucocyte migration test with HBsAg as antigen in the early stages of acute hepatitis (Dudley et al., 1972b; Frei et al., 1973; Yeung Laiwah et al., 1973; Irwin et al., 1974; Ibrahim et al., 1975). In vivo, this blocking effect might act to prevent $\mathbf{T}$ cell damage to infected hepatocytes and, while this could be important in the maintenance of infection in patients with chronic liver disease, it is probably irrelevant in acute hepatitis at the time of clinical presentation as immunofluorescent examination of liver biopsies usually shows that there are no remaining infected cells (Portmann et al., 1976). We have not examined any patients in the incubation stage immediately before the onset of liver damage and it is entirely possible that the blocking effect does not occur until the virus infected hepatocytes begin to be destroyed, this also being the time when antigen/antibody complexes would begin to be formed.

If the theory of immunopathogenesis of viral hepatitis outlined earlier is correct, then the peak aspartate aminotransferase level in acute hepatitis, presumably reflecting the rapidity and extent of liver cell destruction, should be dependent on both the number of infected hepatocytes and the intensity of the immune attack. Although it is difficult to quantitate accurately either of these variables it is nevertheless of interest that it was possible to predict the aminotransferase level, with reasonable accuracy, from a combination of the peak titre of $\mathrm{HBsAg}$ which must, at least in part, reflect the number of infected cells-and the minimum migration index, which has been shown in other situations to correlate with the intensity of a delayed skin reaction (Søborg, 1967).

The finding of migration inhibition with the liverspecific lipoprotein as antigen in half of the cases tested at presentation and its disappearance in the next few weeks is consistent with the suggestion that viral infection might temporarily stimulate a response to this membrane component. We have proposed that $\mathrm{T}$ lymphocytes reacting with membrane associated HBsAg could be responsible for stimulating autoreactive cells by exerting a "helper effect' (Eddleston and Williams, 1974), and it was of interest that the only significant difference between those with and without detectable sensitisation to the lipoprotein was the intensity of the immune response to $\mathrm{HBs} \mathrm{Ag}$, as reflected by the minimum migration index observed with this antigen. In a recent study lymphocyte cytotoxicity for isolated rabbit hepato- cytes was detected in 13 of 14 patients with acute hepatitis tested within two weeks from the onset of their illness (Cochrane et al., 1976) and it may be that this is a more sensitive indicator of an immune response to the liver membrane lipoprotein (Thomson et al., 1974).

We are grateful to the Wellcome Trust for their continued support. W. M. L. was in receipt of an Eli Lilly Fellowship from the American College of Physicians and W. D. R. of a Raine Travelling scholarship from the University of Western Australia.

\section{References}

Alberti, A., Realdi, G., Tremolada, F., and Cadrobbi, P. (1975). HBAg on liver-cell surface in viral hepatitis. Lancet, 1, 346.

Baldwin, R. W., Price, M. R., and Robins, R. A. (1973). Inhibition of hepatoma-immune lymph-node cell cytotoxicity by tumour-bearer serum, and solubilized hepatoma antigen. International Journal of Cancer, 11, 527-535.

Bradstreet, C. M. P., and Taylor, C. E. D. (1962). Technique of complement fixation test applicable to the diagnosis of virus diseases. Monthly Bulletin of the Ministry of Health and Public Health Laboratory Service (London), 21, 96-104.

Brostoff, J. (1974). Critique of present in vitro methods for the detection of cell-mediated immunity. Proceedings of the Royal Society of Medicine, 67, 514-516.

Cochrane, A. M. G., Moussouros, A., Smith, A., Thompson, A. D., Eddleston, A. L. W. F., and Williams, R. (1976). Auto-immune reaction to a liver-specific membrane antigen during acute viral hepatitis. Gut, 17, 714-718.

Currie, G. A., and Basham, C. (1972). Serum mediated inhibition of the immunological reactions of the patient to his own tumour: a possible role for circulating antigen. British Journal of Cancer, 26, 427-438.

Doniach, D., Roitt, I. M., Walker, J. G., and Sherlock, S. (1966). Tissue antibodies in primary biliary cirrhosis, active chronic (lupoid) hepatitis, cryptogenic cirrhosis and other liver diseases and their clinical implications. Clinical and Experimental Immunology, 1, 237-262.

Dudley, F. J., Fox, R. A., and Sherlock, S. (1972a). Cellular immunity and hepatitis-associated, Australia antigen liver disease. Lancet, 1, 723-726.

Dudley, F. J., Giustino, V., and Sherlock, S. (1972b). Cellmediated immunity in patients positive for hepatitisassociated antigen. British Medical Journal, 4, 754-756.

Eddleston, A. L. W. F. (1976). Immunology of hepatitis. In Symposium on Advanced Medicine, vol. 12, pp. 63-73. Edited by D. K. Peters. Pitman Medical: Tunbridge Wells.

Eddleston, A. L. W. F., McFarlane, I. G., Mitchell, C. G., Reed, W. D., and Williams, R. (1973). Cell-mediated immune response in primary biliary cirrhosis to a protein fraction from human bile. British Medical Journal, 4, 274-276.

Eddleston, A. L. W. F., and Williams, R. (1974). Inadequate antibody response to $\mathrm{HBAg}$ or suppressor $\mathrm{T}$ cell defect in development of active chronic hepatitis. Lancet, 2 , 1543-1545.

El Sheikh, N., Woolf, I. L., Galbraith, R. M., Eddleston, A. L. W. F., Dymock, I. W., and Williams, R. (1975). e antigen-antibody system as indicator of liver damage in patients with hepatitis B antigen. British Medical Journal, 4, 252-253. 
Fimmel, P. J. (1975). Studies on leukocyte migration inhibition. The role of E-rosette-forming cells in specific antigen-induced inhibition of migration. Journal of Immunology, 115, $135-138$.

Frei, P. C., Erard, P. H., and Zinkernagel, R. (1973). Cellmediated immunity to hepatitis-associated antigen (HAA) demonstrated by leucocyte migration test during and after acute B hepatitis. Biomedicine, 19, 379-383.

Hart, B. I. (1942). Significance levels for the ratio of the mean square successive difference to the variance. Annals of Mathematical Statistics, 13, 445-447.

Ibrahim, A. B., Vyas, G. N., and Perkins, H. A. (1975). Immune response to hepatitis B surface antigen. Infection and Immunity, 11, 137-141.

Irwin, G. R. Jr., Hierholzer, W. J. Jr., Cimis, R., and McCollum, R. W. (1974). Delayed hypersensitivity in hepatitis B: clinical correlates of in vitro production of migration inhibition factor. Journal of Infectious Diseases, 130, 580-587.

Lee, W. M., Reed, W. D., Mitchell, C. G., Galbraith, R. M., Eddleston, A. L. W. F., and Williams, R. (1975). Cellular and humoral immunity to hepatitis B surface antigen in active chronic hepatitis. British Medical Journal, 1, 705-708.

McFarlane, I. G., Wojcicka, B. M., Zucker, G. M., Eddleston, A. L. W. F., and Williams, R. (1977). Purification and characterisation of human liver-specific membrane lipoprotein. Clinical and Experimental Immunology. (In press).

Miller, J., Smith, M. G. M., Mitchell, C. G., Reed, W. D., Eddleston, A. L W. F., and Williams, R. (1972). Cellmediated immunity to a human liver-specific antigen in patients with active chronic hepatitis and primary biliary cirrhosis. Lancet, 2, 296-297.

Mitchell, C. G., and Eddleston, A. L. W. F. (1973). The importance of selecting suitable foetal calf serum for use in the leucocyte migration test. Transplantation, 16, 689-691.
Mitchell, C. G., Smith, M. G. M., Golding, P. L., Eddleston, A. L. W. F., and Williams, R. (1972). Evaluation of the leucocyte migration test as a measure of delayed hypersensitivity in man: suppression of migration inhibition by puromycin. Clinical and Experimental Immunology, 11, 535-541.

Portmann, B., Galbraith, R. M., Eddleston, A. L. W. F., Zuckerman, A. J., and Williams, R. (1976). Detection of $\mathrm{HBsAg}$ in fixed liver tissue-use of a modified immunofluorescent technique and comparison with histochemical methods. Gut, 17, 1-9.

Reed, W. D., Eddleston, A. L. W. F., Stern, R. B., Williams, R., Zuckerman, A. J., Bowes, A., and Earl, P. M. (1973). Detection of hepatitis $B$ antigen by radioimmunoassay in chronic liver disease and hepatocellular carcinoma in Great Britain. Lancet, 2, 690-694.

Reed, W. D., Mitchell, C. G., Eddleston, A. L. W. F., Lee, W. M., Williams, R., and Zuckerman, A J. (1974). Exposure and immunity to hepatitis $\mathrm{B}$ virus in a liver unit. Lancet, 1, 581-583.

Rocklin, R. E., MacDermott, R. P., Chess, L., Schlossman, S. F., David, J. R. (1974). Studies on mediator production by highly purified human $\mathrm{T}$ and B lymphocytes. Journal of Experimental Medicine, 140, 1303-1316.

Søborg, M. (1967). In vitro detection of cellular hypersensitivity in man. Specific migration inhibition of white blood cells from brucella positive persons. Acta Medica Scandinavica, 182, 167-174.

Thomson, A. D., Cochrane, M. A. G., McFarlane, I. G., Eddleston, A. L. W. F., and Williams, R. (1974). Lymphocyte cytotoxicity to isolated hepatocytes in chronic active hepatitis. Nature, 252, 721-722.

World Health Organisation (1970). Memorandum. Bulletin of the World Health Organisation, 42, 957.

Yeung Laiwah, A. A., Chaudhuri, A. K. R., and Anderson, J. R. (1973). Lymphocyte transformation and leucocyte migration-inhibition by Australia antigen. Clinical and Experimental Immunology, 15, 27-34. 